\title{
Mediações como espaço de discurso: a MPB e a formação de uma ideia de "integração nacional"
}

\author{
Mediation as a space for discourse: the MPB and the formation of an idea of \\ "national integration"
}

Mediaciones como espacio de discurso: la MPB y la formación de una idea de "integración nacional"

Diósnio Machado Neto*

Em dezembro de 2015, Chico Buarque foi insultado por um grupo de jovens que questionavam seu apoio ao governo de Dilma Rousseff. Rapidamente as redes sociais repercutiram o caso e a divisão ideológica do país passou a envolver a esfera musical por meio de um dos seus maiores ícones. Também rapidamente surgiu a associação do "gênio da música brasileira" com o Comunismo. Chico de herói passou a ser um bolivariano. Inclusive reavivou-se um texto já esquecido do colunista de $O$ Globo, Rodrigo Constantino, que apontava o equívoco das políticas de inclusão social que exaltavam as minorias e indicavam criminosos como vítimas de um sistema injusto:

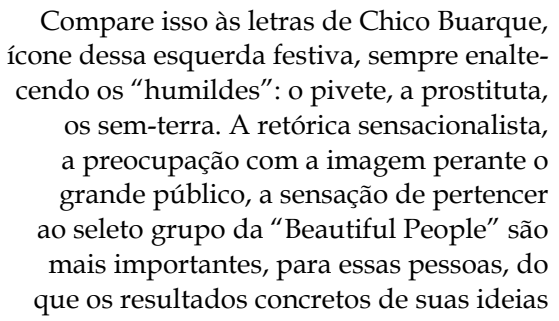

(CONSTANTINO, 2003).

Alguns meses depois outro acontecimento despertou novamente o debate das trincheiras nas redes sociais e trazia, de certo modo, a MPB como um elemento contex-

\footnotetext{
Professor Livre-Docente do Departamento de Música na Faculdade de Filosofia, Ciências e Letras de Ribeirão Preto (FFCLRP-USP). Doutor em Musicologia pela Universidade de São Paulo. E-mail: dmneto@usp.br
}

Recebido em 15/8/2017 - Aprovado em 02/9/2017 http://dx.doi.org/10.5335/hdtv.18n.1.7745 
tual: o filme Aquaruis, de Kleber Mendonça Filho. O enredo tratava da luta de Clara para continuar vivendo em seu apartamento no Edifício Aquarius, quando esse passou a ser alvo do interesse de uma incorporadora imobiliária. Clara era uma mulher símbolo dos anos setenta: progressista e idealista; forjada na luta pela emancipação feminina. Já em sua aposentadoria o seu lugar de vida era mais do que um espaço físico, era o lugar de suas reminiscências. E a trilha sonora de suas memórias era a MPB. As canções eram suas referencias, tanto no profissional, como jornalista cultural, como para as situações de vida; os vinis, a mobília na qual a casa circundava.

Nos dois casos, a MPB é o ponto nevrálgico em que as memórias afloravam aspectos que construíam uma narrativa: as lutas de resistência. Múltiplas resistências, não só políticas, mas de ideologias de vida. Eram pluralidades que compunham um espaço de profundas transformações que vivia o Brasil, a partir de meados da década de 1960. Revelam discursos que articulam tradições da cultura brasileira, contextos sociais e, evidentemente, destacam, para o tempo coevo, os problemas de uma sociedade muito frágil para enfrentar as armadilhas da sociedade dos grandes negócios. Nesse entre-lugares de sentidos que tem o capitalismo sem limites como panorama primeiro, a MPB surgia contextualizando a postura de quem declarava que o sistema se mantinha pela exploração desumana do homem, pela guetificação dos pobres, pela desconsideração da diversidade cultural.

O contrário também é interessante. Nesse mesmo entre-lugares em que a MPB se transformou em ícone, discursos de resistência ao que ela simbolizava ganharam energia. Entre muitos motivos, a rotulação da MPB como espaço de uma cultura anticapitalista prosperou por meio de um cenário musical fragilizado desde a década de 1990, quando gêneros musicais "sintéticos", produzidos em estúdio a partir de algumas referências da cultura popular, foram promovidos pelas grandes gravadoras nacionais. Nesse contexto, o Axé e o Sertanejo Universitário, entre outros gêneros, destinaram à MPB um status de movimento "cult". Até a antiga referência de canção de protesto, ação ativa na forja de uma consciência de mundo, mudou de lugar. Hoje, a cultura política por meio da música popular vem do Funk e do Rap.

Em síntese, a MPB parecia destinada a ser o que sempre foi: o gênero de canção que se associava a uma camada da sociedade mais intelectualizada, moldada por um espírito de inquietude juvenil contestadora e experimentalista. Um movimento musical que moldava um discurso civilizatório e impregnava seus amantes de uma sensação de distinção, tal qual um germânico ouvindo lieds de Schubert ou um americano ouvindo Peter Seeger ou Bob Dylan. Porém, essa imanência cult dos tempo coevos, ou a perspectiva de interpretar o mundo ao seu redor pelo ato de cantar/escutar, permaneceu passiva até os movimentos políticos reacenderem sua importância para a ideia que a MPB sempre simbolizou: um espaço de discussão sobre a nação, tanto no aspecto político, como nas suas raízes culturais.

Esse é o cenário que debate um interessante livro escrito por Luísa Quarti Lama- 
rão, A crista é a parte mais superficial da onda: mediações culturais na MPB (1968-1982), publicado recentemente pela Editora Prismas, a partir da tese defendida pela autora em 2012 no Programa de Pós Graduação em História da Universidade Federal Fluminense. O questionamento que nos leva ao livro parece ser o mesmo da autora. Por que a MPB tem tanta representatividade no nosso coletivo cultural? Quais seriam as forças que nos faz, como Clara, ancorar suas memórias nas canções de Chico, Caetano, Gil, entre outros? E mais que isso, por que em um momento de forte divisão politico-ideológica no Brasil os compositores da MPB passam a ser alvo da fúria dos autoproclamados "libertários"?

Para a autora, o espaço primordial para observar como a MPB se "constituiu" como elo entre uma ideia e uma ação sobre a cultura brasileira é a mediação de agentes culturais. Tais agentes seriam músicos, produtores, críticos que desenvolveram entre final da década de 1960 até 1980 a Indústria Cultural brasileira. Seria nos desafios de racionalizar uma produção artística, inclusive superando a resistência de setores dos intelectuais de esquerda que demonizavam a mercantilização da arte, que a MPB percorreu para ter um significado que transcendeu o seu próprio objeto, a música. Para a autora, em suas primeiras páginas, o estudo da mediação cultural seria uma "outra" forma de estudar a História da Música.

Mesmo ressalvando já de início que a autora concebe o estudo da História da Música sem o estudo da substancia musical propriamente dita, a escolha se justifica numa perspectiva importante, a mediação.
Nessa perspectiva bem delimitada pelas dificuldades de se compreender o processo de consolidação de comunhão entre um segmento da sociedade e um movimento artístico, Lamarão remete a uma ideia consolidada na intelligentsia dos estudiosos da cultura brasileira: a MPB é um espaço que define uma crítica; delimita "hierarquia de gostos" e, de formas diversas; identifica posições sobre uma cultura política e sues paradigmas. Porém, a MPB serviu de espaço para uma profunda contradição da época: a relação do mercado com a arte. Apresenta um dilema crucial, que a MPB se forja numa identidade constituída não mais num tipo ideal de cultura, como o homem iluminado para as coisas do nacional, como projetava Mário de Andrade, mas na identidade formada "relação com o mercado".

Esse ponto é crucial na definição do problema, pois, como diz a autora, "ocorre, portanto, a redefinição do senso de pertencimento e identidade, organizado cada vez menos por lealdades locais ou nacionais e mais pela participação em comunidades de consumidores" (LAMARÃO, 2012, p. 62). Assim o objetivo do texto está em "refletir sobre o papel e o poder dos mediadores, entendidos aqui como intelectuais - de que forma eles têm, em determinado período, influído nos acontecimentos. E qual ganho buscam observar os mediadores (músicos, produtores, críticos, e a própria indústria) para entender a MPB? Para a partir dela ser feita uma análise positiva de todos os intermediários humanos e materiais da 'performance' e do 'consumo' de arte, de gestos e corpo a palcos e mídias". Essa perspectiva, seguindo o raciocínio da autora, é necessá- 
rio porque existem contradições potentes, e mitos enraizados, que permeiam a MPB, pois a MPB teria cooptado energias antagônicas, como o posicionamento de militâncias políticas com os aspectos mercadológicos da Indústria Cultural, dentro de um regime ditatorial de matriz conservador.

Outro ponto importante para compreender o caminho da autora é a desconstrução que faz sobre a cultura de massa. Contrariando o cacoete de parte de uma intelectualidade que infringe à cultura de massa uma visão danosa ao desenvolvimento de uma crítica social ou de uma postura de resistência política, Lamarão não teme ao afirmar que uma das funções da cultura de massa é a mediação, a comunicação. Essa comunicação, no caso da MPB, promoveu, e também se valeu, de um discurso que desde Manoel de Araújo Porto Alegre se faz presente no imaginário da nação: a sua redenção pelo popular.

De que forma a MPB teria se consolidado nessa plataforma? Primeiro, a autora afirma que "não necessariamente a música perde qualidade por ter se tornado 'mercadoria'” (LAMARÃO, 2012, p. 10). A mediação cultural, como parte integrante do sistema capitalista em que foi constituída a MPB, contribuiu para a ascensão desse gênero musical." Segundo porque a cultura de massa provoca uma horizontalização das relações de acesso, permitindo que haja uma dinâmica de amplo aspecto na constituição dos discursos, em que as diversas matrizes que formam o edifício social passam a ser ativas no processo de constituição do patrimônio cultural que os representa. Nos vórtices dessas dinâmicas, apesar das estratégias de persuasão pela racionalização do consume, ocorrem quebras hierarquias que abrem universos de verbalização antes encobertos pela patrimonialização dos bens culturais representativos do coletivo. E mais que isso, é inútil pensar que há uma "fuga" desse processo da racionalização social na qual a Indústria Cultural seria um agente único de transformação, o que ocorre é uma retroação "mediada", na qual a Indústria Cultural seria uma parte dessa mediação:

Se a cultura contemporânea não pode se desenvolver sem os públicos massivos, a noção de povo - vista como parte da massificação social - também não pode ser imaginada como um lugar autônomo. Nessa mesma direção, a cultura dita "de elite", assim como a popular, não pode ser percebida como um reduto incontaminado, uma vez que já foi incorporada ao mercado e à comunicação industrializada (LAMARÃO, 2012, p. 65).

Nessa perspectiva, o texto parte para organizar campos de escutas e experiências musicais que operam o ato de mediação, de produção de sentido. No caso da MPB, Lamarão estrutura sua base de análise sobre três agentes: produção (músicos, repertories, arranjos, formação de bandas); consumo (marketing e agentes de vendas); circuito social e veiculação e seu alcance (universidades, casas de shows, programas de auditórios).

A autora busca compreender como os agentes mediadores - "profissionais que, na cadeia produtiva da cultura, trabalha com diversas linguagens, sabendo dialogar com as fontes de financiamento, os artistas e os públicos" (LAMARÃO, 2012, p. 73) justamente serviram de elo a um processo 
complexo que consolida a MPB em muitos aspectos: 1. dentro de um processo socioeconômico de modernização capitalista do Brasil; 2. no caminho de estruturação da Indústria Cultural; 3. no diálogo com a tradição do modernismo-nacionalista ainda presente nas discussões sobre arte; 4 . na interface de um processo político repressivo, num mundo que clamava pela renovação de postura diante das antigas estruturas de poder que haviam levado a sociedade a guerras que não faziam mais sentido; 5 . todas as situações amparadas pelo desenvolvimento técnico e das formas de comunicação de massa que "aproximavam" realidades e descortinavam cotidianos, ou os fantasiavam.

Esses problemas seriam observados atuando na constituição da mediação que não só legitimou, mas deu representatividade à MPB ao ponto de criar por ela uma tradução do Brasil. Nessa análise se poderia, inclusive, dar luz à uma percepção do que seria uma contradição vital do movimento: uma "práxis cultural dos jovens" (LAMARÃO, 2012, p. 83), logo inerentemente vinculada à contestação das estruturas socioeconômicas do tempo, convivendo, e se afirmando, numa perspectiva econômica como mercadoria de produção e distribuição de massas. O que se poderia observar era:

[...] o conjunto de atividades produtivas de representação e significação na sociedade que participa da mediação cultural. Abre-se a possibilidade de se trabalhar com a ideia de cultura popular industrializada como 'mediação cultural' numa noção próxima à empregada por Adorno ao se referir à obra de arte, que reconhece o produto cultural como elemento no qual a sociedade se objetiva (LAMARÃO, 2012, p. 66).
Em outras palavras, a autora estrutura seu espaço de análise tratando de sistematizar as contradições do momento, e por elas busca analisar os meandros internos das construções que ao fim e ao cabo determinaram o impacto que a MPB teve, e tem, no cenário cultural e artístico do Brasil. Por suas palavras:

[...] o surpreendente resultado foi que a cultura e as artes daquele período incorporaram, a um só tempo, formas de resistência e formas de cooptação e colaboração, diluídas num gradiente amplo de projetos ideológicos e graus de combatividade e crítica, entre um e outro polo (LAMARÃO, 2012, p. 58).

A primeira esfera que analisa a autora são os próprios compositores. Ponto crucial nessa geração, que saía dos Festivais da Record com uma demanda de posicionamento político, foi entender a lógica do mercado e ao mesmo tempo equacionar algumas forças vivas que determinavam a articulação social da proposta artísticas desses compositores. Lamarão afirma que o campo de negociação no qual a afirmação da MPB ocorreu foi justamente num momento em que a ideia de uma arte revolucionária perdeu força e que as esperanças libertárias no progresso tecnológico não ocorreu. A perda da utopia iluminista pela "socialização da cultura" abriu espaços para que o mercado assumisse um projeto de discurso sobre progresso que acabou por aglutinar a Indústria e a juventude. Essa energia foi potencializada numa pauta estética articulada dentro das energias históricas da tradição nacional-popular da música.

A ambiguidade tornou-se a força do modelo discursivo. Popular passou a ser o 
que "mais se vendia" e não a expressão espontânea de um segmento social. Ao mesmo tempo, esse popular era medido por uma classe média intelectualizada que tinha demandas de consumo distantes do que passou-se a chamar "música brega"; o que incluía os boleros e fados da Era do Rádio. Também paralelamente não se desconhecia o ideal de música engajada, como fora a tônica da Era dos Festivais, porém esse não poderia estar vinculado a uma tradição do cânone ideológico, pois esse "vedava o acesso à modernidade". Assim, na confluência das estratégias de mercado com o contexto político e as plataformas de renovação de sentido de um segmento importante da sociedade - a juventude - formou-se um discurso que promovia uma metonímia da presença: a música dessa geração foi despolitizada - enquanto produto -, porém assumia a contestação por novas formas de politização. Como diz a autora, instalou-se “a ênfase na importância das questões relativas à prática do cotidiano, à dúvida e à descrença no alcance do projeto revolucionário na arte e, por extensão, nas formas de militância política tal como foram encaminhadas pela geração anterior" (LAMARÃO, 2012, p. 91).

A primeira mediação discutida por Luísa Lamarão foi a promoção de um projeto de difusão de conhecimento assumido por editoras, em especial a Editora Abril. Um dos campos de atuação foi a música, lançado coleções sobre música clássica. Sem atentar para o fato do que o projeto de civilização pela expansão da Cultura Artística já tinha referencias no Brasil - vide todos os periódicos sobre música que surgiram no princípio do século XX, como a Gazeta Musical (Rio de Janeiro) ou a Revista Música (da Sociedade de Concertos Sinfônicos de São Paulo) - a autora constrói a sua ideia de espaço de mediação. Em outras palavras, a ação editorial: um espaço de articulação do público com o produto cultural.

Assim, na esteira dessa iniciativa de entrelaçar a grande arte com o público jovem, Lamarão justifica o surgimento de uma coleção sobre a História da Música Popular Brasileira, em 1970. Seria nessa coleção que alguns paradigmas da MPB teriam sido apresentados ao público, principalmente o que apresenta o movimento na intersecção do resgate da tradição do popular-nacional com a estética de vanguarda. Nessa senda que se formaram os discursos sobre os autores, ou como afirma a autora, o caráter mediador da coleção. Assim a coleção aproxima Noel Rosa, o compositor que "inventou" a ideia de canção para as massas de Chico Buarque, o mito que resgatava o samba por uma roupagem contemporânea; inclusive lançando os fascículos lado a lado. Se Chico era a tradição, Caetano era apresentado como inventor, experimentalista, renovador. E assim, criando o discurso de energias que se redescobriam na tradição, a coleção forjava um espaço de compartilhamento para uma ideologia da época, a "integração nacional". Aliás, ideia também compartilhada pelo regime militar e que acabou por incorporar setores da intelectualidade de esquerda, como afirma a autora.

Assim, percorrendo os fascículos da História da Música Popular Brasileira, a autora vai descortinando os léxicos e estruturas discursivas que consubstanciavam a MPB pelos 
textos de redatores, como Affonso Romano de Sant' Anna. Por ele que a autora apresenta um ponto importante na forja do artista da MPB como a voz que denuncia a realidade. E essa ideia do "dia que virá" reconfigurada de sua acepção original tornou-se tão importante como outros elementos de representação do artista da MPB e sua áurea heroica, como a canção no elo com "crescimento espiritual" ou na expressão do multiculturalismo. A ideia do "dia que virá" era a solução da própria validade do cantor na mediação com a realidade política.

Já na segunda esfera de mediação, Luísa Lamarão se dedica aos críticos. Constrói sua análise considerando que, se os veículos de comunicação criaram uma estratégia de divulgação, foram os críticos que transformaram a MPB num "produto cultural". Inicia sua trajetória localizando a formação do pensamento crítico sobre a música popular na década de 1950. Afirma que os Festivais foram fundamentais para formar um compromisso de opinião, pois eles se tornaram espaços de disputas que só pode ser resolvido pelo jornalismo cultural diante do Tropicalismo: o que estava em jogo era um processo de renovação de antigas tradições. Ao exercitar essa visão, os críticos se tornaram verdadeiros analistas do desenvolvimento cultural brasileiro. Essa afirmação a leva a separar as gerações de críticos sublinhando que os que se vincularam à MPB a ideia do Brasil da diversidade e da gente jovem disposta a mudanças. Na verdade, era uma relação de autopoiese dentro do processo de afirmação do movimento.

Nessa análise da atividade do jornalismo cultural, Lamarão observa a formação dos estandartes, como o mito da resistência e o estilo da pichação como forma de embate. Da mesma forma vislumbra os espaços de discordância primordiais: a origem da música brasileira e a questão da mercantilização da obra de arte. Por fim, já estabelecidos no espaço que lhes conferia autoridade passam a criar parâmetros de legitimidade, discorrendo sobre a natureza do ato criativo; a qualidade técnica para o exercício da crítica e, inclusive, crítica social pela qual afirmavam a missão e penúria da MPB diante o "gosto popularesco da sociedade".

Como conclusão, Lamarão afirma que a principal ação dessa crítica foi resolver para o público a dicotomia entre arte e capitalismo: "incentivar o consumo das obras, mas sem esquecer que uma de suas características era questionar certos elementos da sociedade capitalista" (LAMARÃO, 2012, p. 182).

Por fim, o último mediador que enraíza a MPB como elemento primordial de tradução de uma época, ou uma ideologia, foi o espaço. Para Lamarão, o problema surgido na relação da MPB dentro da Indústria Cultural acabaram por encontrar o espaço natural da próprio movimento: os circuitos universitários. Costurando as reações das estratégias de mercado, que acabavam centrando os investimentos em poucos artistas, com as questões dos custos de divulgação e o esgotamento do modelo de festivais, a MPB encontrou um espaço que harmonizava as diversas características e tensões do movimento. $\mathrm{O}$ circuito universitário não só se mostrava economicamente atrativo, pelo baixo investimento, como aproximava a MPB de sua ideologia: uma música inte- 
lectualizada. Essa harmonia garantiu, desde 1972, o sucesso das bilheterias.

Lamarão explica convicentemente que o sucesso do modelo se desdobrou em muitos fenômenos. Primeiro que o modelo se tornou uma marca, mas, também, vulgarizou o termo. Suscitou críticas dos próprios artistas que viam o espaço por diversos ângulos, desde ser apenas mais um palco até ser um espaço sectário de posturas ideológicas incompatíveis com o tempo. Também observa que pelo circuito universitário o regime promoveu um projeto cultural de peso, o Projeto Pixinguinha. Por ele estabeleceu um ideário já bem conhecido, a busca de uma cultura de integração baseada em uma "herança histórica e artística nacional".

Todo esse processo analítico leva a autora a conclusões contundentes. Primeiro, insiste que há uma construção narrativa da esquerda sobre o período militar que é hegemônica na atualidade, e, nessa narrativa, a MPB surge como símbolo de resistência. No entanto, contesta essa ideia partindo do pressuposto que a sociedade na qual se dirigia a MPB não era homogênea e nem ao menos a música era sempre engajada aos problemas sociopolíticos de seu tempo. Também a impossibilidade de separar a MPB do mercado poria em cheque a perspectiva de pureza ideológica; inclusive considerando que a MPB modelou o próprio mercado, ou seja, foi uma mediadora em relação à Indústria Cultural. Sua conclusão considera, então, que a principal marca da MPB, e o motivo de sua transcendência na memória política e/ ou emotiva da geração que a acompanhou foi construída pela sua capacidade de equacionar a questão da "nação integrada". Esse fenômeno só pode ocorrer por sua organicidade com a Indústria Cultural:

Assim, a indústria cultural no Brasil interpretou, em termos mercadológicos, uma identidade nacional. A ideia de "nação integrada" propagandeada pelo Estado passou a representar a interligação dos consumidores potenciais espalhados pelo território nacional. Curiosamente, o projeto cultural das esquerdas foi incorporado ao plano do regime militar de valorização da cultura popular, destacando seu objetivo de educar, auxiliando na construção da nação. A mediação cultural, por sua vez, permitiu a circulação das ideias e da cultura de esquerda. E a indústria cultural transformou a resistência em mercadoria (LAMARÃO, 2012, p. 245).

Em outras palavras, a MPB se mitificou pela conjunção de forças de um momento: o do desenvolvimento do capitalismo no Brasil. Assim navegando em águas impregnadas de seus contrários conseguiu potencializar, inclusive, a tradição do nacional-popular. Porém tudo isso só seria possível pela mediação de agentes culturais constituídos na plataforma desse processo capitalista:

Por fim, se considerarmos a mediação como a possibilidade de circulação de bens culturais em determinada sociedade, as três fontes aqui apresentadas fecham esse círculo: os artistas que se apresentavam em shows do "Circuito Universitário" eram retratados nos fascículos que percorriam também todo o Brasil e eram analisados nos artigos de jornal pela "nova crítica" da década de 1970. Assim, um elo alimentava o outro, fazendo a movimentação necessária nesse "mar", colocando a MPB "na crista da onda" (LAMARÃO, 2012, p. 247).

Todo o trajeto percorrido no texto consolida fortemente uma perspectiva que nasce com a New Musicology: o objeto musical 
em si é uma parte da compreensão sobre o impacto da música na sociedade. É imprescindível compreendermos a pluralidade de fenômenos que se desdobram no processo sociocomunicativo. Assim, uma História da Música estaria muito além da compreensão dos gêneros e da genealogia dos artistas. Estaria também em compreender inúmeros outros processos, entre eles as estruturas de produção e divulgação. Assim, é extremamente contemporâneo pensar nas mediações que ocorrem para compreender o processo. No entanto, tais mediações só podem ser vistas em toda sua amplitude se considerado o objeto de pesquisa em sua primeira natureza: a música.

Sem a análise da música, parte fundamental da observação da força motriz é perdida. Faltam em trabalhos como o de Luísa Lamarão a compreensão de como a música projeta os sentidos e provoca a mediação. A canção não existe somente pela letra, poderia dizer algum crítico mais voraz. É necessário que projetos como esse se abram para campos interdisciplinares ou mesmo parta de uma perspectiva transdisciplinar do próprio pesquisador. Sem essa perspectiva creio que parte considerável do fenômeno a ser estudado se perde. Ficam de fora elementos fundamentais que determinam a empatia do movimento com seu público. Perde-se, por exemplo, como os processos de significação (a metaforização da música e suas estruturas de escuta compartilhada) atuam na relação de vínculo afetivo com o público. Perde-se a essência do que é a discussão do nacional, em questões de música (o que não ocorreu com Mário de Andrade). Ressente o texto da compreensão do que era a experiência estética de vanguarda usada nos arranjos de Rogério Duprat (não era apenas adorno a foto de Karlheinz Stockhausen na capa de Sgt Pepper's); ou qual a simbiose musical operada por Chico Buarque na tradição do samba; ou porque do vínculo de Walter Franco, em Revolver, com a linguagem pós tonal. Poderíamos continuar na serialização de diversos tipos de "ou" para expor o quão frágil fica uma análise de um movimento musical quando a música, e sua linguagem, estão fora dos parâmetros analisados.

Apenas como espaço de reflexão poder-se-ia dizer que a mediação se potencializa, e principalmente no caso da MPB, mais na música do que nas letras. Como compreender a MPB sem estar atento à captação de uma energia que juntava a grande tradição cancioneira do Brasil, inclusive da tradição da música erudita se levássemos em consideração os pontos de contato, a zona intermediária, na qual as experiências estéticas de compositores como Villa Lobos, Cláudio Santoro e Gilberto Mendes, para citar alguns, foram assimiladas dentro da MPB. Agora uso como refrão o afirmado anteriormente: "não era apenas adorno a foto de Karlheinz Stockhausen na capa de Sgt Pepper's". Há que ter treinamento específico para compreender as aberturas de sentido que obras capitais da MPB tinham: como o uso tópico do Berimbau em Domingo no Parque; a compreensão das métricas populares, e suas tropificações, sendo a essência da linguagem de Caetano Veloso; todos os recursos das quebras dos fluxos métricos usados por Tom Zé.

Enfim, compreender os elementos musicais do experimentalismo que tornou-se o 
principal capital da MPB seria vital para fortalecer as considerações sobre as mediações. Foi no trato dos gêneros, transformados em gêneros expressivos, ou gêneros metamorfoseados, que os compositores de MPB conseguiram um lastro com muitas memórias afetivas que justificam o fenômeno da "nação integrada". Sem dúvida, isso ocorreu. $\mathrm{Na}$ simbiose de ritmos, o Brasil se reconheceu sem precisar cada um de nós nos rendermos aos programas de educação folclórica dos tempos anteriores à MPB.

Por fim, ao não analisar a música, a autora perdeu de vista algumas energias que deram a condição à mediação, ou melhor, forjaram a mediação. Energias fundamentais que enraizaram a MPB como espaço de integração de muitas culturas, não apenas a utopia da integração nacional: 1 . do nacionalismo modernista que tratava o Brasil como uma rapsódia de lugares unidos por uma metafísica definida por sua natureza exuberante e que só poderia ser traduzida por um lirismo épico; 2. da vanguarda (e isso justifica o envolvimento de Rogério Duprat) que militava no campo oposto do modernismo nacionalista e viu na MPB um espaço de intervenção ideal em que novos sons levariam a uma amplificação da escuta crítica que poderia provocar uma reação contra a mecanização crítica imposta pela indústria cultural, usando a energia da própria indústria cultural; 3. Enfim, de um espírito do tempo permitia que tantas expressão diferentes fossem aglutinadas na representação de uma condição expressiva: a abertura para novas experiências (inclusive permitia incluir o rock e a soul music como música brasileira).
Enfim, essas considerações provisórias são apenas para pontuar que o excelente livro de Luísa Lamarão deve incentivar para pesquisas mais transdisciplinares. Isso porque, a excelente interpretação dos mediadores culturais que deram condição de enraizamento mitológico à MPB poderia alcançar maiores espaços de observação se tivessem considerado a música. Assim, ouso dizer, inclusive, que há muito pouca musicologia em trabalhos sobre a música popular brasileira. O que é uma profunda contradição, já que a canção tem sua força (ou deveria ter desde a revolução do madrigalismo seiscentista) justamente na relação semântica com a palavra.

\section{Nota}

1 A resenha foi realizada sobre a tese para obtenção do título de Doutor em História (Departamento de História da Universidade Federal Fluminense) de Luísa Quarti Lamarão, A crista é a parte mais superficial da onda: mediações culturais na MPB (1968-1982), defendida em 2012. Disponível em: <http://www.historia.uff.br/stricto/ td/1423.pdf $>$. O texto foi lançado pela Editora Prismas (Curitiba), em 2017.

\section{Referências}

CONSTANTINO, Rodrigo. Mais Lobão e menos Chico Buarque. O Globo. 14 maio 2003. Disponível em: <https://oglobo.globo.com/ opiniao/mais-lobao-menos-chico-buarque-8375227>. Acessado em: 13 set 2017.

LAMARÃO, Luísa Quarti. A crista é a parte mais superficial da onda: mediações culturais na MPB (1968-1982). 2012. Tese (Doutorado em História) - Departamento de História Universidade Federal Fluminense, Rio de Janeiro. 2012. 